\title{
Pemilihan Strategi Pemasaran di Era Digital pada Kelompok Ibu PKK Desa Gadingharjo
}

\author{
Antonius Satria Hadi*1, Ardhi Khairi² \\ 1,2Program Studi Kewirausahaan, Fakultas Ekonomi, Universitas Widya Mataram \\ *e-mail: antonius_satria@widyamataram.ac.id
}

\begin{abstract}
Community engagement activities in the form of counseling to mothers of family empowerment and welfare in Gadingharjo Village, Sanden Sub-District, Bantul Regency is aim to provide additional understanding, knowledge, and training to mothers of family empowerment and welfare (PKK) in Gadingharjo Village in choosing the right marketing strategy in digital era and industry 4.0 so the products can be marketed widely by utilizing an application-based marketplace that is currently being popular in Gadingharjo Village, namely Shopee application. Counseling aims to provide additional understanding, knowledge, and training to mothers of PKK in Gadingharjo in choosing the right marketing strategy in digital era and industry 4.0 with lecturing, demonstrating, question \& answer, and practicing methods. The benefits that can be obtained by participants from community service activities are increased knowledge and understanding of mothers of PKK in Gadingharjo about industry 4.0 and about choosing digital marketing strategies by utilizing an applicationbased marketplace.
\end{abstract}

Keywords: Digital era, Industry 4.0, Marketing strategy, Marketplace.

\begin{abstract}
Abstrak
Kegiatan pengabdian kepada masyarakat berupa penyuluhan kepada kelompok ibu PKK di Desa Gadingharjo, Kecamatan Sanden, Kabupaten Bantul bertujuan untuk memberikan pemahaman, pengetahuan tambahan, dan pelatihan kepada ibu-ibu PKK di Desa Gadingharjo dalam memilih strategi pemasaran yang tepat di era digital dan industri 4.0 agar produk yang sudah ada dapat dipasarkan secara luas dengan memanfaatkan marketplace berbasis aplikasi yang saat ini sedang populer khususnya di Desa Gadingharjo, yaitu aplikasi Shopee. Penyuluhan bertujuan untuk memberikan pemahaman, pengetahuan tambahan, dan pelatihan kepada ibu-ibu PKK di Desa Gadingharjo dalam memilih strategi pemasaran yang tepat di era digital dan industri 4.0 yang dilakukan dengan metode ceramah, demonstrasi, tanya jawab, serta praktik secara langsung. Manfaat yang dapat diperoleh peserta dari kegiatan pengabdian kepada masyarakat ini antara lain meningkatnya pengetahuan, pemahaman, dan pengalaman ibu-ibu PKK di Desa Gadingharjo tentang tentang industri 4.0 dan tentang pemilihan strategi pemasaran digital dengan memanfaatkan marketplace berbasis aplikasi.
\end{abstract}

Kata kunci: Era digital, Industri 4.0, Strategi pemasaran, Marketplace.

\section{PENDAHULUAN}

Desa Gadingharjo termasuk dalam wilayah Kecamatan Sanden Kabupaten Bantul. Sebagian besar mata pencaharian masyarakat adalah petani, yang mencapai $60 \%$, sedangkan yang berprofesi sebagai wirausaha hanya $4 \%$. Hasil pertanian tersebut antara lain adalah bawang merah, cabai, padi, palawija, pertanian kawasan pesisir, sengon, akasia, pisang, kelapa. Dengan mayoritas profesi masyarakat adalah sebagai petani, maka diperlukan alternatif untuk menambah penghasilan diluar pekerjaan pokok tersebut dengan tidak mengurangi porsi kerja mereka, salah satunya adalah dengan berwirausaha atau dengan memasarkan hasil pertanian tersebut menggunakan strategi pemasaran daring dalam era digital.

Kemajuan teknologi modern seperti sensor, sistem fisik siber, internet untuk segalanya (IoT), otomatisasi mesin, dan lain-lain memengaruhi setiap bidang kehidupan sehari-hari (Hariharasudan \& Kot, 2018). Memasuki era revolusi industri 4.0 seperti sekarang ini, sangatlah penting untuk memahami dan mengimplementasikan strategi pemasaran digital yang tepat, khususnya untuk masyarakat di pedesaan. Industri 4.0 sendiri adalah tren terbaru teknologi yang sedemikian rupa canggihnya, yang berpengaruh besar terhadap proses produksi pada berbagai 
sektor. Teknologi canggih tersebut termasuk artificial intelligence (AI), e-commerce, big data, fintech, shared economies, hingga penggunaan robot. Istilah industri 4.0 pertama kali diperkenalkan pada Hannover Fair 2011, yang ditandai dengan revolusi digital (Prasetiantono, 2018). Salah satu wujud dari strategi pemasaran digital seperti yang dijelaskan di atas adalah ecommerce yang dikarenakan pembeli dapat dengan mudah melakukan transaksi (Azizah et al., 2019). Dengan demikian, masyarakat di pedesaan khususnya di Desa Gadingharjo perlu memahami dan mengimplementasikan strategi pemasaran yang tepat di era digital sebagai alternatif untuk menambah penghasilan.

Tabel 1. Presentase Mata Pencaharian Warga Desa Gadingharjo

\begin{tabular}{lc}
\hline Jenis Mata Pencaharian & Jumlah (\%) \\
\hline Petani & 60 \\
Buruh & 23 \\
PNS/TNI/Polri & 8 \\
Wirausaha & 4 \\
Lain-lain & 5 \\
\hline Sumber: gadingharjo.bantulkab.go.id/index.php/first/artikel/34
\end{tabular}

Bagi seorang wirausaha khususnya di Desa Gadingharjo, pada industri 4.0 harus memanfaatkan setiap kesempatan untuk memperkenalkan diri dan usahanya, karena fungsi pemasar adalah melekat pada diri seorang wirausaha dan juga harus dapat memilih strategi pemasaran yang tepat di era digital sekarang ini. Memperkenalkan diri tidak harus diikuti dengan berjualan, tetapi tidak menutup kemungkinan untuk melakukan hal itu jika respon dari lawan bicara menunjukkan ketertarikan kepada produk (Lukiyanto, 2017).

Teknologi digital mungkin semakin menjadi pusat kehidupan sosial dan ekonomi (McGuigan \& Murdock, 2015). Sekitar 10 tahun terakhir kita telah menyaksikan perubahan besar dalam cara pertukaran barang secara digital antara pembeli dan penjual (Ghazawneh \& Henfridsson, 2015). Dengan demikian diperlukan pemasaran digital untuk mendukung pertukaran barang tersebut. Pada dasarnya, pemasaran digital merupakan bagian dari komunikasi pemasaran. Komunikasi pemasaran sendiri adalah sarana yang digunakan perusahaan untuk menginformasikan, membujuk, dan mengingatkan konsumen - secara langsung atau tidak langsung — tentang produk dan merek yang mereka jual (Kotler et al., 2017). Salah satu unsur penting dalam pemasaran digital adalah dengan memanfaatkan marketplace berbasis aplikasi. Marketplace digital semakin memuaskan permintaan konsumen akan barangbarang yang diinginkannya (Selander et al., 2013).

Saat ini marketplace berbasis aplikasi yang sedang populer di Desa Gadingharjo, yaitu aplikasi Shopee. Kelompok ibu PKK di Desa Gadingharjo sebagian besar sudah mempunyai ponsel cerdas tetapi belum dapat memaksimalkan fungsi dari ponsel cerdas tersebut untuk mengimplementasikan strategi pemasaran digital serta belum sepenuhnya memahami tentang strategi pemasaran digital di era industri 4.0. Adapun beberapa dari mereka sudah mempunyai produk tetapi belum dipasarkan secara luas. 
Berdasarkan paparan di atas, maka dirasa perlu adanya penyuluhan tentang memilih strategi pemasaran digital yang tepat di era industri 4.0 serta memberi pelatihan dalam praktik pemasaran digital dengan memanfaatkan aplikasi Shopee kepada pelaku usaha kelompok ibu PKK. Maka kegiatan ini diharapkan mampu memberikan pemahaman, pengetahuan, dan motivasi tambahan kepada kelompok ibu PKK di Desa Gadingharjo dalam memilih strategi pemasaran digital yang tepat di era industri 4.0 agar produk yang sudah ada dapat dipasarkan secara luas serta.

\section{METODE}

Khalayak sasaran kegiatan yang dipilih adalah ibu-ibu PKK di Desa Gadingharjo, Kecamatan Sanden, Kabupaten Bantuk, Provinsi DIY. Kegiatan dilaksanakan di ruang pertemuan Desa Gadingharjo dengan jumlah khalayak sasaran yaitu sebanyak 22 orang. Pelaksanaan kegiatan pengabdian berlangsung pada hari Sabtu, 20 Oktober 2018, mulai pukul 08.00 s.d. pukul 15.30 WIB. Penyuluhan bertujuan untuk memberikan pemahaman, pengetahuan tambahan, dan pelatihan kepada kelompok ibu PKK di Desa Gadingharjo dalam memilih strategi pemasaran digital yang tepat di era industri 4.0 yang dilakukan dengan metode ceramah, tanya jawab, demonstrasi, serta praktik secara langsung.

Metode ceramah, diskusi, dan tanya jawab dilakukan untuk memberikan pemahaman dan pengetahuan tentang strategi pemasaran digital dan industri 4.0. Sedangkan metode demonstrasi dan praktik untuk mengajarkan penggunaan aplikasi Shopee, mulai dari membuat akun sampai menjual secara daring. Peralatan yang digunakan dalam penyuluhan dan pelatihan ini adalah laptop, proyektor, video penunjang materi, ponsel cerdas, dan aplikasi Shopee.
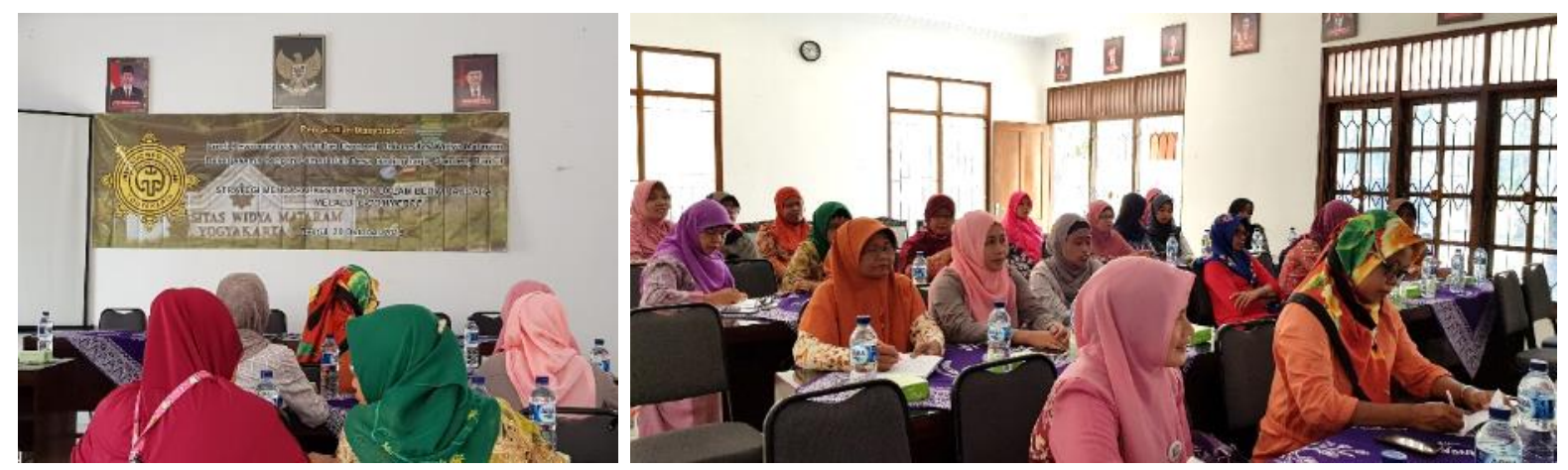

Gambar 1. Khalayak Sasaran Kegiatan Kelompok Ibu PKK di Desa Gadingharjo

\section{HASIL DAN PEMBAHASAN}

Sebelum kegiatan dilaksanakan, maka dilakukan persiapan-persiapan, antara lain: (1) Melakukan studi pustaka tentang industri 4.0 serta pemilihan strategi pemasaran digital bagi ibuibu PKK di Desa Gadingharjo; (2) Melakukan persiapan alat dan bahan untuk penyuluhan dan pelatihan tentang industri 4.0 serta pemilihan strategi pemasaran digital bagi kelompok ibu PKK di Desa Gadingharjo; (3) Menentukan waktu pelaksanaan dan lamanya kegiatan pengabdian; (4) Menentukan dan mempersiapkan materi yang akan disampaikan dalam kegiatan pengabdian masyarakat. 
Tabel 2. Jadwal Kegiatan

\begin{tabular}{llllll}
\hline No & \multicolumn{1}{c}{ Kegiatan } & \multicolumn{3}{c}{ Bulan Oktober minggu } \\
\cline { 3 - 5 } & & \multicolumn{3}{c}{ ke- } \\
\cline { 3 - 5 } & & & & & \\
\hline 1 & Peninjauan Lokasi & & & & \\
\hline 2 & Proses Perizinan & & & & \\
\hline 3 & Penyuluhan dan Pelatihan di Lokasi & & & \\
\hline 4 & Pembuatan Laporan Akhir & & & \\
\hline
\end{tabular}

Penyuluhan dilaksanakan dengan khalayak sasaran kegiatan 22 orang kelompok ibu PKK di Desa Gadingharjo. Pelatihan dimaksudkan untuk memberikan informasi bagaimana memanfaatkan seluruh fasilitas yang ditawarkan oleh aplikasi Shopee. Setelah pelatihan selesai dilaksanakan, diharapkan peserta dapat langsung melakukan penjualan dan memasukkan produk yang siap dipasarkan. Materi tentang pemilihan strategi pemasaran digital di era industri 4.0 serta pelatihan memanfaatkan marketplace berbasis aplikasi Shopee telah tersampaikan dengan baik dan dapat diterima oleh khalayak sasaran kegiatan. Indikatornya adalah adanya tanya jawab yang interaktif antara pengabdi dengan khalayak sasaran kegiatan.

Selama kegiatan berlangsung, kegiatan pengabdian pada masyarakat ini memberikan hasil sebagai berikut: (1) Meningkatnya pengetahuan dan pemahaman kelompok ibu PKK di Desa Gadingharjo tentang industri 4.0 dan pemilihan strategi pemasaran digital. Hal ini dapat terlihat dari peran serta yang sangat aktif oleh peserta dalam kegiatan tanya jawab yang dilakukan pada saat pemaparan materi tentang industri 4.0 dan pemasaran digital. Peserta memperoleh pemahaman tentang pergesaran teknologi yang semakin modern serta memperoleh tambahan informasi tentang berbagai ragam marketplace salah satunya adalah aplikasi Shopee; (2) Meningkatnya pengetahuan dan pemahaman kelompok ibu PKK di Desa Gadingharjo tentang penggunaan dan pemanfaatan marketplace berbasis aplikasi Shopee, mulai dari mempraktikkan membuat akun baru sampai dengan melakukan uji coba penjualan.
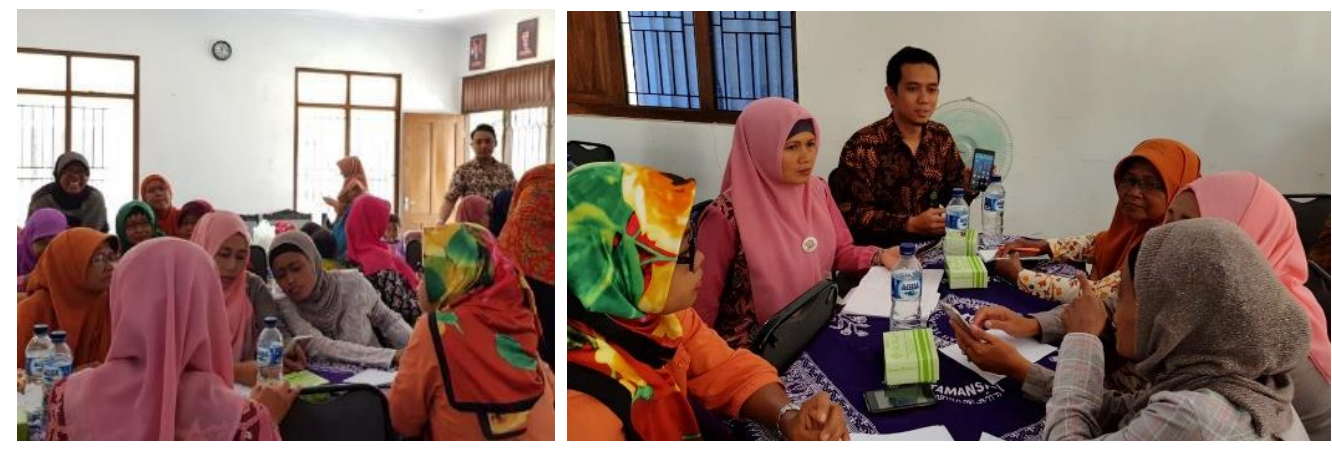

Gambar 2. Suasana Diskusi dan Tanya Jawab tentang Industri 4.0 \& Pemasaran Digital

Adapun beberapa faktor pendukung dan penghambat selama kegiatan pengabdian ini dilaksanakan. Faktor yang mendukung terlaksananya kegiatan pengabdian pada masyarakat ini adalah besarnya minat dan antusiasme peserta selama kegiatan, sehingga kegiatan berlangsung dengan lancar dan efektif. Serta peserta pun sudah melek teknologi dan sudah mempunyai ponsel cerdas. Sedangkan faktor penghambatnya adalah fasilitas peralatan yang minim, dalam hal ini adalah adanya beberapa peserta yang tidak mempunyai ponsel cerdas serta tidak tersedianya fasilitas wi-fi. 


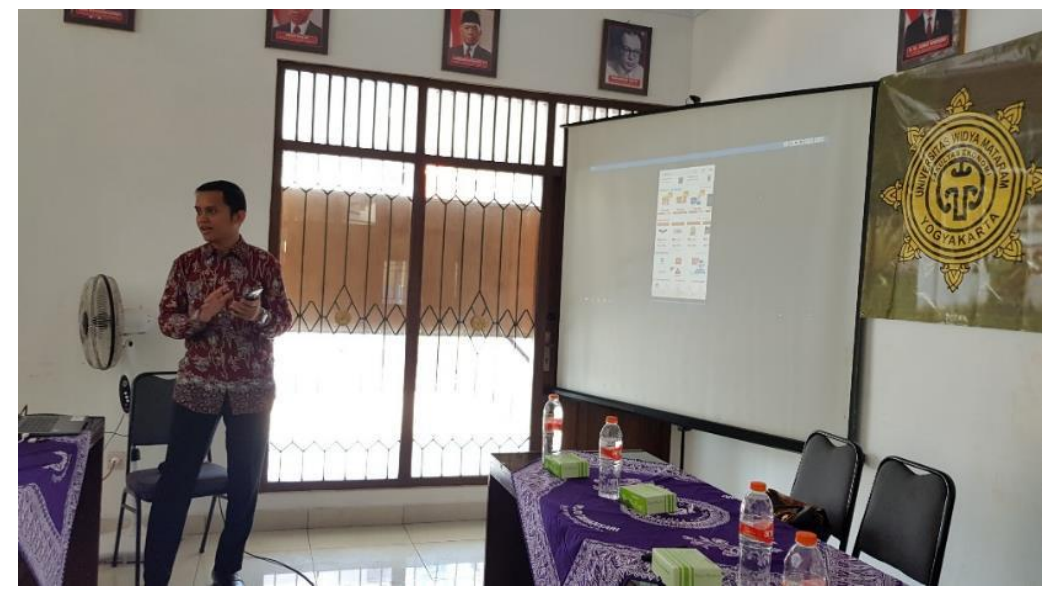

Gambar 3. Pengabdi Sedang Mendemonstrasikan Aplikasi Shopee

\section{KESIMPULAN}

Penggunaan teknologi digital telah memengaruhi semua aspek kegiatan manusia, termasuk pemasaran. Pemasaran berbasis digital digunakan untuk memperoleh konsumen, membangun preferensi mereka, promosi merek, memelihara konsumen, serta meningkatkan penjualan yang pada akhirnya meningkatkan profit. Pemasaran digital memungkinkan pembeli memperoleh seluruh informasi mengenai produk dan bertransaksi melalui internet, dan memungkinkan penjual untuk memantau dan menyediakan kebutuhan serta keinginan calon pembeli tanpa batasan waktu dan geografis. Pemasaran digital juga merupakan cara komunikasi dua arah yang dapat menimbulkan kesadaran dan engagement masyarakat terhadap produk dan merek tertentu (Purwana et al., 2017).

Dari kegiatan pengabdian pada masyarakat ini dapat disimpulkan bahwa pengetahuan dan pemahaman kelompok ibu PKK di Desa Gadingharjo tentang industri 4.0, pemilihan strategi pemasaran digital, dan pemanfaatan marketplace berbasis aplikasi Shopee menjadi meningkat, mulai dari membuat akun baru sampai dengan melakukan penjualan disertai dengan penggunaan yang berkelanjutan, agar menumbuhkan kepercayaan kepada para konsumen yang nantinya berujung pada niat membeli ulang secara daring (Hong \& Cho, 2011; Liu \& Tang, 2018). Dengan meningkatnya pengetahuan dan pemahaman tentang pemasaran digital serta pemanfaatan marketplace, maka selanjutnya kelompok ibu PKK dapat terus menggunakan aplikasi Shopee.

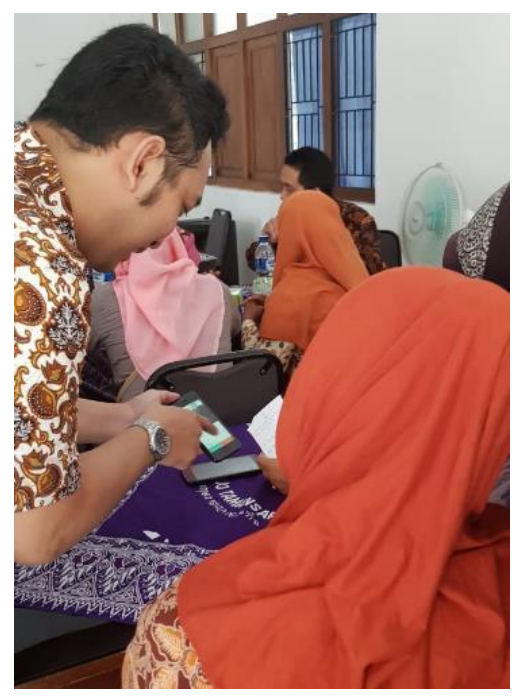

Gambar 4. Pengabdi Sedang Mempraktikan Penggunaan Aplikasi Shopee 


\section{SARAN}

Mengingat besarnya manfaat kegiatan pengabdian pada masyarakat ini, maka selanjutnya perlu: (1) Mengadakan pelatihan yang lebih mendalam tentang bagaimana mempraktekkan strategi pemasaran digital melalui media yang lainnya, misalnya laptop; (2) Mengadakan sosialisasi dan pelatihan serupa pada kelompok ibu PKK atau bahkan masyarakat di desa dan kecamatan lain dengan materi yang hampir serupa; (3) Adanya kesinambungan program pasca kegiatan pengabdian ini sehingga kelompok ibu PKK di Desa Gadingharjo dapat benar-benar mempraktekan keterampilan pemasaran digital; (4) Adanya evaluasi lanjutan setelah kegiatan guna mengetahui apakah materi dan pelatihan yang disampaikan betul-betul dipraktekkan secara berkelanjutan.

\section{UCAPAN TERIMA KASIH}

Ucapan terimakasih disampaikan kepada 1) Aan Indra Nursanta, S.S. selaku Lurah Desa Gadingharjo; 2) Kelompok ibu PKK di Desa Gadingharjo, Kecamatan Sanden, Kabupaten Bantul; 3) Lembaga Penelitian Pengabdian Masyarakat (LPPM) UWM; 4) Fakultas Ekonomi Universitas Widya Mataram.

\section{DAFTAR PUSTAKA}

Azizah, N., Erly Rofianti Wahyudi, Khoirrun Nissa, Amelia Fibrianti Wahyudi, \& Siti Khoiruli Ummah. (2019). "Pemberdayaan Istri Nelayan Melalui Pelatihan Digital Marketing Strategy (DMS) Darah Biru”, Dinamisia: Jurnal Pengabdian Kepada Masyarakat, 3(1), 131-141.

Ghazawneh, A., \& Henfridsson, O. (2015). "A paradigmatic analysis of digital application marketplaces", Journal of Information Technology, 30(3), 198-208.

Hariharasudan, A., \& Kot, S. (2018). "A scoping review on digital english and education 4.0 for industry 4.0", Social Sciences, 7(11), 1-13.

Hong, I.B. and Cho, H. (2011), "The impact of consumer trust on attitudinal loyalty and purchase intentions in B2C e-marketplaces: intermediary trust vs. seller trust", International Journal of Information Management, 31(5), 469-479.

Kotler, Philip., Kertajaya, Hermawan., Setiawan, Iwan. (2017). Marketing 4.0: Moving from Traditional to Digital. John Wiley \& Sons, Inc., Hoboken, New Jersey.

Liu, Y., \& Tang, X. (2018). "The effects of online trust-building mechanisms on trust and repurchase intentions", Information Technology \& People, 31(3), 666-687.

Lukiyanto, Kukuh (2017). Entrepreneur Sebagai Marketer. Diakses pada Oktober 2018, tersedia di: http://binus.ac.id/malang/2017/09/entretrepreneur-sebagai-marketer/.

McGuigan, L., \& Murdock, G. (2015). "The medium is the marketplace: Digital systems and the intensification of consumption", Canadian Journal of Communication, 40(4), 717-726.

Prasetiantono, A. Tony (2018). Revolusi Industri 4.0. Diakses pada Oktober 2018, tersedia di: https://psekp.ugm.ac.id/2018/04/10/revolusi-industri-4-0/.

Purwana ES., Rahmi., Aditya, Shandy. (2017). "Pemanfaatan Digital Marketing Bagi Usaha Mikro, Kecil, dan Menengah (UMKM) di Kelurahan Malaka Sari, Duren Sawit", Jurnal Pemberdayaan Masyarakat Madani, 1(1), 1-17.

Selander, L., Henfridsson, O. and Svahn, F. (2013). "Capability Search and Redeem across Digital Ecosystems”, Journal of Information Technology, 28(3), 183-197. 